\title{
Toolkit for resilience assessment of critical infrastructures to earthquake induced soil liquefaction disasters
}

\author{
Mariantonietta Morga, Keith Jones \\ Anglia Ruskin University, Chelmsford, United Kingdom
}

Contacting author: mariantonietta.morga@anglia.ac.uk

\begin{abstract}
The critical infrastructure resilience depends on several factors that go beyond the physical reliability and capacity to repair the system after a disruption. The overall critical infrastructure resilience includes aspects related to the social and economic backbone governing its capacity to deliver its service. This contribution presents a theoretical toolkit to calculate the overall resilience of critical infrastructures developed within the European project LIQUEFACT for earthquakeinduced soil liquefaction disasters. The toolkit combine several aspects organized in three dimensions: organizational and management, the physical or technical system and operational capacity to deliver the service. The toolkit clearly defines also resilience aspects, such as preparedness, absorption, recovery and adaptation. For each dimension and aspect of the resilience several indicators are developed. A critical and technical explanation of each indicator is here proposed, as well a systematic methodology to combine them in the resilience toolkit. The novelty of this study is the systematic analysis of dimensions, aspects and indicators that made the proposed resilience toolkit original. The study is concluded with analyses of feasibility of the toolkit to natural disasters and applicability to localized disasters, such as earthquake-induced soil liquefaction events. Finally, the key factors of toolkit influencing a built asset model of critical infrastructures are identified.
\end{abstract}

Keywords: resilience; critical infrastructures; soil liquefaction; earthquakes; built asset management.

\section{Introduction}

In the last two decades, countless studies about Critical Infrastructure $(\mathrm{Cl})$ resilience were proposed in literature. Some of those researches presented methods to calculate the resilience as capacity of $\mathrm{Cl}$ network to recover after a disaster. In this case, the resilience is measured in term of velocity it needs to get back to the same performance level it was before a disaster occurrence [2]. Those studies includes only the $\mathrm{Cl}$ system capacity to recover. As highlighted by some scholars [1], the performance assessment of the $\mathrm{Cl}$ network combines data related to the physical, economic aspects of the infrastructure and its impact on the society including cascade effects on other infrastructures, business activities and normal life to the community. In [2] and [3], a framework for resilience appraisal was proposed including robustness, redundancy, resourcefulness and rapidity. Among those determinants of the resilience, the rapidity indicates the recovery velocity of a system; hence, it can be considered as a synonymous of what is defined "engineering resilience". Although such framework was proposed to appraise the community resilience, $\mathrm{Cls}$ are the principal organizations having extreme importance for the community to disaster 
response, such as earthquakes, and speed up its recovery [3]. Therefore, the infrastructure resilience is a component of the community resilience.

Few studies indicated resilience at the pre-disaster preparation through mitigation actions on the physical assets besides the capacity of the community to respond to the disaster [2,3]. In this prospective, Tierney and Bruneau [2] identified in their holistic resilience appraisal framework four different dimensions of the community resilience: technical, organizational, social and economic. However, whilst the first dimension can be directly associate to the resilience of $\mathrm{Cls}$ identified as subsystems of the community system, the second dimension is related to organizations managing $\mathrm{Cls}$. The economic dimension looks at the ability of reducing direct and indirect economic losses; finally, the social dimension is related to social subsystem and it is intended as community capacity to absorb the impact due to the disaster. The only exception being the social dimension, all the other dimensions can be applied to $\mathrm{Cls}$ in wide sense. The last two dimensions are related to social and institutional subsystems of the community. In the model proposed by Bruneau et al. [3], preparedness is a critical element implemented in the practice to improve the community resilience. It is intended both as the measures to reduce the impact and as implementation of policies to respond to the disaster. Those two aspects of the disaster preparedness can be applied also to the Cls. Whilst the disaster impact can be reduced by improving the reliability of physical elements of the infrastructures to exceptional loads; the response to disaster is enhanced by introducing trainings for the personal, devoting economical resources to overcome future disasters.

Sharifi and Yamagata [7] proposed five dimensions for the community resilience; environmental; social; economic; infrastructure and physical; and institutional. The infrastructure and physical is clearly related to infrastructures; however, reading the definitions of the economic and institutional dimensions it is clear they are related to the economic and organisational aspects of the community, but they can be adapted to single organizations, such as $\mathrm{Cls}$.
Proag [4] mentioned the difference between hard resilience and soft resilience proposed by Moench [5]. Whilst the first is the physical strengthen of structures and institutions; the second is the absorption and recovery abilities of the system, which are related to the adaptive capacity of the system itself. Proag [4] refers also to adaptability as both a way to respond to threats and an approach related to preparedness, as defined by Handmer and Dovers [6].

Other scholars, i.e. Sharifi and Yamagata [7], distinguished four abilities for the community resilience after Larkin and Fox-Lent [8]: planning; absorption; recovery; and adaptation. These abilities are applied to Liquefact $\mathrm{Cl}$ reliance assessment toolkit, which is presented in this work.

Including a temporal prospective to the concept of resilience by defining it as the system ability to absorb a shock and reorganize after the event, it is a dynamic system property [9] contrarily to risk or robustness. Besides to have been defined a determinant of resilience [2], the system robustness is the opposite of vulnerability [9], which is defined for a specific instant or a time span, depending on the study subject. This definition of resilience implicating the capacity to reorganize is based on the system adaptive capacity. The temporal prospective of resilience leads to the identification of three distinguished resilience elements: readiness and preparedness; response and adaption; recovery and adjustment [10, 11]. Rodriguez-Nikl [13] emphasized the temporal prospective of resilience by distinguishing two elements of the resilience: robustness of a system to an external shock and rapidity to recover from it. The first is measured by the functionality of the system, whilst the second one by the recovery time.

While in several studies the adaptation capacity is defined as an element or ability of resilience, in the Disaster Resilience of Place (DROP) model proposed by Cutter et al. [12], it is a system characteristic related to its resilience but not one of its elements. On the other hand, those scholars defined community resilience as a capacity of a social system to recover from disaster by absorbing and adapting. They also distinguished few dimensions among the community resilience, 
including the infrastructure one. The organisational dimension is related to the institutional aspects of the community according those scholars [12]. The adaption and absorption capacities of the system inform also the definition proposed by Bhamra and Burnard [10] who identified two aspects of resilience by analysing it respect to Small and Medium Enterprises (SMEs): persistence and stability of the system affected by a disruption. Whilst the first is the system capacity to absorb disturbance and hold its own function after the disaster; the second is the system ability to return to the equilibrium state, also by adapting itself [10].

The before reviewed literature about the resilience distinguishes dimensions and abilities, also called aspects by some scholars. Moreover, the review showed also the $\mathrm{Cl}$ resilience is considered a dimension of the wider concept of community resilience. I special toolkit for the appraisal of such resilience dimension is needed. It should collect indicators related to the different sub-dimensions of $\mathrm{Cls}$. This article presents the $\mathrm{Cl}$ resilience assessment toolkit defined in Liquefact project, which investigates community resilience to Earthquake Induced Liquefaction Disasters (EILD). The toolkit background is presented in the following section, while the third section introduces the tool itself. Finally, analysis and conclusions presented based on comparison respect to previous works are presented.

\section{Critical Infrastructures resilience indicators}

Few tools and toolkits for $\mathrm{Cl}$ resilience assessment were proposed in literature. Among those some were selected, analysed, compared, modified and enhanced to define the Liquefact $\mathrm{Cl}$ resilience assessment toolkit. This toolkit aims to assess the $\mathrm{Cl}$ resilience to EILDs. This kind of disaster is due to a natural hazard. The occurrence likelihood of natural hazards can be predicted, as well the vulnerability to specific hazard intensity, expecially for physical assets. The Earthquake Induced Liquefaction events are characterized by a short duration of the shock; as consequence, the system absorption can be stretched along a short period of time. Because of those characteristics not all measures proposed proposed in literature can be applied to EILDs.

First, the $\mathrm{Cl}$ Resilience framework proposed by the National Infrastructure Advisory Council [14] is selected. It identifies few factors affecting the overall resilience of infrastructures. Among them, which are listed in Table 1, few are selected because they be applied to the case of $\mathrm{Cl}$ resilience to IELDs, as shown in the third column of the table. Another scholar, Prior, identified indicators to measure the $\mathrm{Cl}$ resilience [15]. Prior proposed two frameworks for the resilience assessment: one for the a-priori appraisal and one for the post-hoc one [15]. Few of those post-hoc factors are the same resilience measures listed among the a-priori factors and highlight the adaptive capacity of real systems that faced disruptive events. Nevertheless, the Liquefact $\mathrm{Cl}$ resilience toolkit is meant to be used for the resilience a-priori appraisal. For such reason Table 2 contains only the resilience indicators identified by Prior for that appraisal [15]. Finally, the Critical Infrastructure Resilience Assessment Tool (CI-RAT) defined within the European H2O20 project RESILENS is analysed to define the Liquefact $\mathrm{Cl}$ resilience toolkit [16]. ClRAT aims also to appraise the a-priori $\mathrm{Cl}$ resilience; hence it values of its indicators could be used to inform a resilience management plan including three aspects: preparation and protection; mitigation, absorption and adaptation; response, recovery and learning. Those resilience management stages are different from the resilience aspects identified by Larkin et al. [8]. RESILENS project developed also a tool for the post-hoc evaluation of the $\mathrm{Cl}$ resilience [16], which is neglected in this analysis. In CI-RAT tool the resilience indicators are classified according three domains: organizational, technological, and societal. A summary of the indicators collected in this tool are shown in Table 3. The CI-RAT was used in RESILENS project to define a resilience scorecard.

CI-RAT and Prior's indicators, as well the National Infrastructure Advisory Council factors were identified for a wide range of disasters, so not all of them can be applied to appraise $\mathrm{Cl}$ resilience to EILDs. 
Table 1. Cl Resilience framework proposed by the National Infrastructure Advisory Council [14]

\begin{tabular}{|c|c|c|c|}
\hline Category [14] & Factor [14] & $\begin{array}{l}\text { Applicable } \\
\text { to EILDs }\end{array}$ & $\begin{array}{l}\text { Dimensions and indicators of } \\
\text { Liquefact } \mathrm{Cl} \text { resilience toolkit }\end{array}$ \\
\hline \multirow{5}{*}{$\begin{array}{l}\text { Infrastructure design and asset } \\
\text { characteristics }\end{array}$} & Interconnectedness & $\mathrm{Y}$ & Service (Inherent resilience) \\
\hline & Asset profile & Y & Technical (Repair) \\
\hline & Product/Service profile & $\mathrm{Y}$ & Service (Reinstate) \\
\hline & Design limitations & & \\
\hline & Cyber dependence & $\mathrm{Y}$ & Service (Inherent resilience) \\
\hline \multirow{2}{*}{ Supply chain vulnerability } & Availability of critical components & $\mathrm{Y}$ & Service (Reinstate) \\
\hline & Domestic sources & $\mathrm{N}$ & - \\
\hline \multirow{2}{*}{ Sector interdependencies } & Dependencies & Y & Service (Reinstate) \\
\hline & Co-location & $\mathrm{N}$ & - \\
\hline \multirow{2}{*}{ Sector risk profile } & High-profile target & $\mathrm{N}$ & - \\
\hline & Strategic assets & $\mathrm{N}$ & - \\
\hline \multirow{2}{*}{$\begin{array}{l}\text { Markets and regulatory } \\
\text { structure }\end{array}$} & Regulatory constraints & Y & Coordination \\
\hline & Market structure & $\mathrm{N}$ & - \\
\hline \multirow{2}{*}{$\begin{array}{l}\text { Public-private roles and } \\
\text { responsibilities }\end{array}$} & High-impact, Low frequency risks & Y & Management (Responsibility, culture) \\
\hline & Disaster coordination & Y & $\begin{array}{c}\text { Management (Communication, } \\
\text { external stakeholder) }\end{array}$ \\
\hline Standards & Standard bodies & Y & Management (Regulation) \\
\hline \multirow{2}{*}{ Information sharing } & Threat information & $\mathrm{Y}$ & Management (Communication) \\
\hline & Clearances & $\mathrm{N}$ & - \\
\hline Workforce issues & Capabilities & Y & Management (Training, leadership) \\
\hline
\end{tabular}

Table 2. Cl resilience indicators collected by the Risk and Resilience Group [15]

\begin{tabular}{|c|c|c|c|}
\hline Category [15] & Indicator [15] & $\begin{array}{l}\text { Applicable to } \\
\text { EILDs }\end{array}$ & $\begin{array}{l}\text { Dimensions and indicators of } \\
\text { Liquefact } \mathrm{Cl} \text { resilience toolkit }\end{array}$ \\
\hline \multirow{9}{*}{ A-priori } & Probability of failure & Y & Management (Risk analysis) \\
\hline & Quality of infrastructure & Y & Technical \\
\hline & Pre-event functionality of the infrastructure & Y & Technical (Repair) \\
\hline & Substitutability & Y & Technical (Redundancy) \\
\hline & Interdependence & Y & Service (Supply chain) \\
\hline & Quality/extent of mitigating features & Y & Technical (Repair) \\
\hline & Quality of disturbance planning/response & Y & Technical (Inherent resilience) \\
\hline & $\begin{array}{l}\text { Quality of crisis communications/information } \\
\text { sharing }\end{array}$ & Y & $\begin{array}{c}\text { Management (Communication } \\
\text { and external stakeholder) }\end{array}$ \\
\hline & Security of infrastructure & $\mathrm{N}$ & - \\
\hline
\end{tabular}


Table 3. Cl resilience components included in CI-RAT tool [16]

\begin{tabular}{|c|c|c|c|}
\hline Requisite [16] & Elements [16] & $\begin{array}{l}\text { Applicable } \\
\text { to EILDs }\end{array}$ & $\begin{array}{l}\text { Dimensions and indicators of Liquefact } \\
\qquad \mathrm{Cl} \text { resilience toolkit }\end{array}$ \\
\hline \multirow{6}{*}{$\begin{array}{l}\text { Preparedness, } \\
\text { prevention, } \\
\text { protection }\end{array}$} & Organization and coordination & $\mathrm{Y}$ & $\begin{array}{l}\text { Management (Responsibility, Disaster } \\
\text { Management (DM) HR plan) } \\
\end{array}$ \\
\hline & $\begin{array}{c}\text { Organization dynamics including leadership, } \\
\text { culture, decision making, internal and } \\
\text { external relationship }\end{array}$ & Y & $\begin{array}{l}\text { Management (Leadership, culture, } \\
\text { external stakeholders) }\end{array}$ \\
\hline & $\begin{array}{l}\text { Budget and financial capacity including } \\
\text { budget for protection, redundancy, financial } \\
\text { capacity to realize allocated budget }\end{array}$ & $\mathrm{Y}$ & $\begin{array}{c}\text { Management (Disaster } \mathrm{M} \text { budget and } \\
\text { Resilience budget, Business Contingency } \\
\text { Plan (BCP)) }\end{array}$ \\
\hline & Risk management & Y & $\begin{array}{c}\text { Management (Risk analysis, security } \\
\text { plan, regulations) and Technical (Security } \\
\text { procedures) }\end{array}$ \\
\hline & $\begin{array}{c}\text { Safeguarding } \mathrm{Cl} \text { assets with electronic and } \\
\text { physical means }\end{array}$ & $\mathrm{N}$ & - \\
\hline & Safeguarding mission critical systems & $\mathrm{N}$ & - \\
\hline \multirow{4}{*}{$\begin{array}{l}\text { Mitigation, } \\
\text { absorption and } \\
\text { adaptation }\end{array}$} & Building codes and infrastructure hardening & $\mathrm{Y}$ & $\begin{array}{l}\text { Technical (Building codes, redundancy } \\
\text { planning, repair) }\end{array}$ \\
\hline & $\begin{array}{c}\text { Early warning and information management } \\
\text { systems }\end{array}$ & $\mathrm{Y}$ & $\begin{array}{l}\text { None - Element not considered in } \\
\text { Liquefact project }\end{array}$ \\
\hline & Robustness, redundancy and backup & Y & $\begin{array}{l}\text { Technical and Operational (Planned } \\
\text { redundancy, inherent resilience) }\end{array}$ \\
\hline & Immediate actions & Y & Management (Evacuation plan, BCP) \\
\hline \multirow{4}{*}{$\begin{array}{l}\text { Response, } \\
\text { recovery and } \\
\text { learning }\end{array}$} & $\begin{array}{l}\text { Education and learning including training, } \\
\text { education, openness and improvement }\end{array}$ & Y & $\begin{array}{c}\text { Management (Training, learning from } \\
\text { others) }\end{array}$ \\
\hline & $\begin{array}{l}\text { Responsiveness including business continuity } \\
\text { planning and exercises }\end{array}$ & Y & Management (Simulation exercises, BCP) \\
\hline & Resource provision & $\mathrm{Y}$ & Management, Technical and Operational \\
\hline & $\begin{array}{l}\text { Learning from others, i.e. actions and } \\
\text { information sharing }\end{array}$ & Y & $\begin{array}{l}\text { Management (Learning from other, } \\
\text { communication) }\end{array}$ \\
\hline
\end{tabular}

\section{Liquefact $\mathrm{Cl}$ Resilience tool}

Liquefact $\mathrm{Cl}$ resilience assessment toolkit for EILDs [17] combines the experience of the before presented past researches in the field of $\mathrm{Cl}$ and community resilience and introduces improving it by introducing systemic prospective. It identifies $\mathrm{Cls}$ as a set of assets characterized by complementary functions and the common aim of delivering a service. Figure 1 shows an enhanced version of this toolkit, already presented in [17]. It contains indicators classified according both dimensions, also called categories in [14] and domains in [16], and aspects, which are otherwise indicated as requisites in [16]. The dimensions of
Liquefact toolkit are organization and management, technical systems, and operational delivery systems. The first two dimensions are similar to those proposed in Resilens CI-RAT [16], whereas the last one is associated with to systemic prospective of $\mathrm{Cls}$ introduced in Liquefact. Each toolkit dimension numbers sub-dimensions and those of the technical dimension, i.e. physical asset and asset infrastructure, highlight the systemic prospective of the toolkit. 


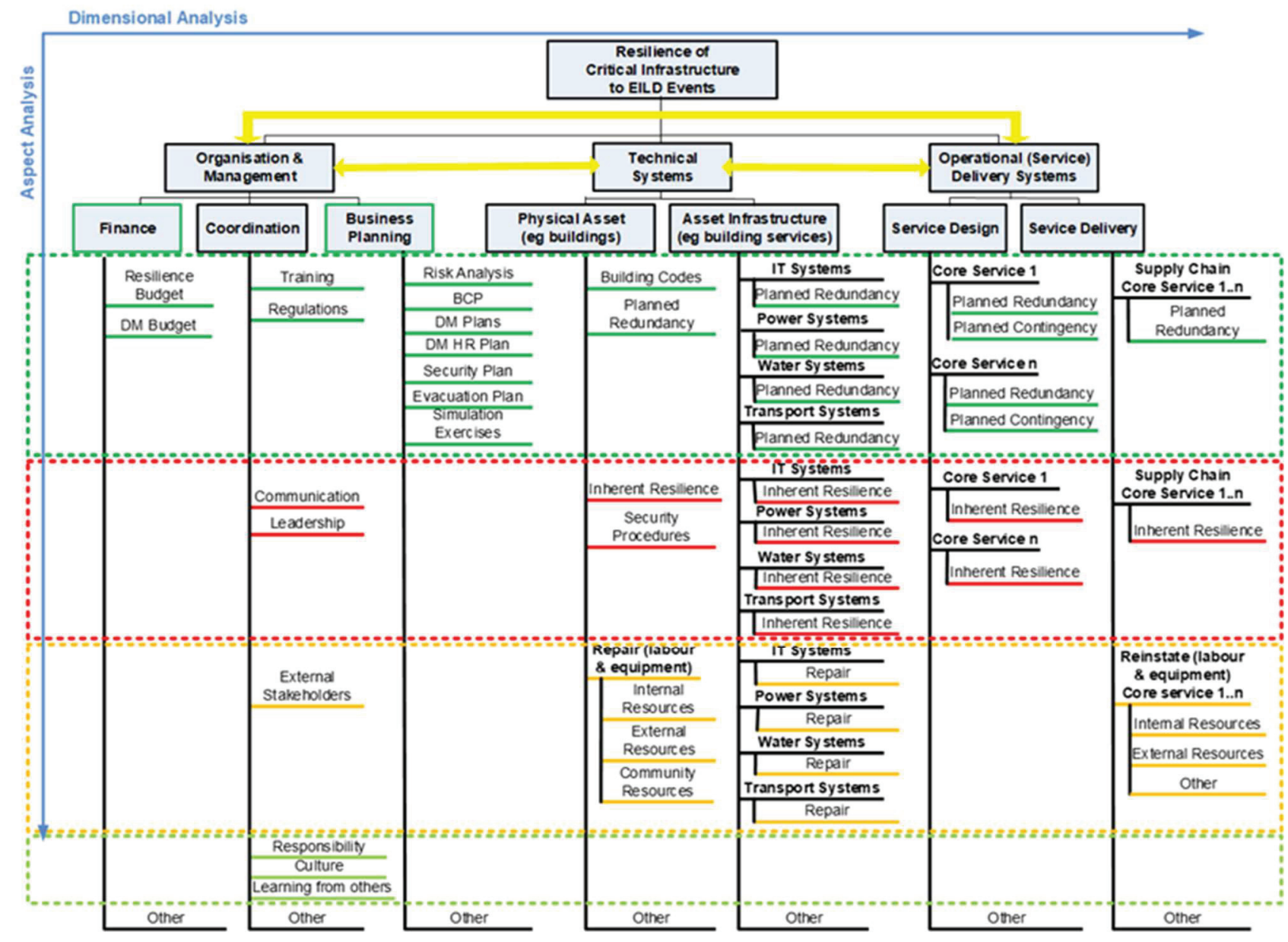

Figure 1. Liquefact $\mathrm{Cl}$ resilience tool

The Liquefact $\mathrm{Cl}$ resilience assessment toolkit proposes indicators equivalent to elements collected in RESILENS CI-RAT [16], factors of Berkeley and Wallace's framework [14] and indicators of Prior's a-priori resilience tool. The forth column of Table 1, 2 and 3 shows the equivalence.

The improved Liquefact $\mathrm{Cl}$ resilience assessment toolkit proposed in the work classify the resilience indicators according to aspects proposed by Larkin et al [8] for community resilience: preparation, absorption, recovery and adaptation. In Figure 2 this work presents also the correlation between those resilience aspects and the time-line of the disruptive event. The Figure 2 highlights that the adaptation of a $\mathrm{Cl}$ system informs the preparation to a new similar disaster and hence it can be considered a new improved preparedness of the $\mathrm{Cl}$ system.

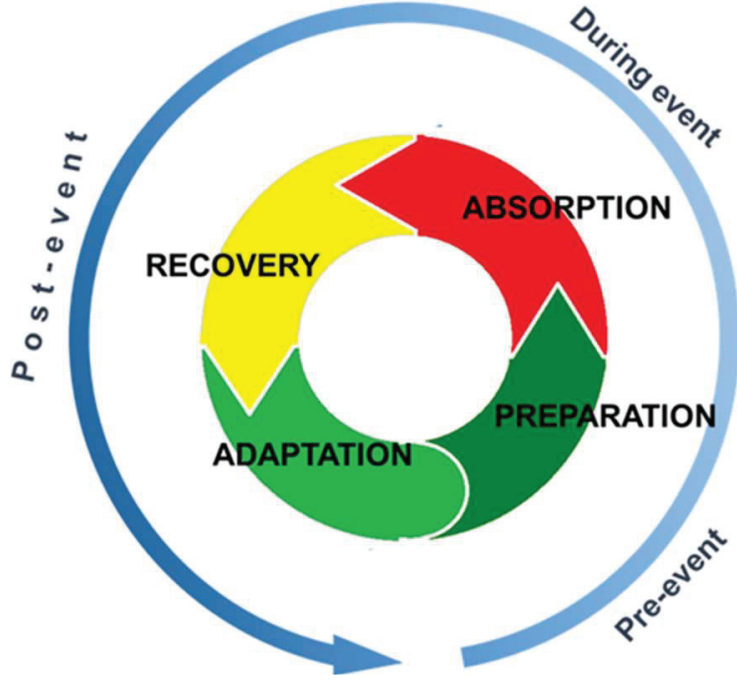

Figure $2 \mathrm{Cl}$ resilience aspects and their correspondence to disaster phases as proposed in Liquefact project 
Liquefact $\mathrm{Cl}$ resilience assessment toolkit has some advantages respect to the models ([14], [15], [16]) analysed to define it. It proposes a hierarchic organization of resilience indicators respect to resilience dimensions and sub-dimensions. Still, a transversal resilience assessment of the $\mathrm{Cl}$ respect a single aspect is possible because of the classification of its indicators also according to aspects: this is a strong point of this Liquefact toolkit. Moreover, The Liquefact toolkit merges indicators related to physical parts of a $\mathrm{Cl}$ and those oriented to the appraisal of the organizational part: this makes the tool applicable to both hard and soft Cls. In fact, whilst the first ones base their service delivery mostly on the functionality of the physical assets; the service delivery of the soft $\mathrm{Cl}$ depends on both social and organizational ability of single workers and the overall infrastructure hierarchic structure and often the economic capacity of the infrastructure. Examples of the hard $\mathrm{Cls}$ are power, hydraulic, telecommunication and transportation networks; while civil protection are local and national organizations are listed among soft Cls. Finally, to understand the advantages of Liquefact $\mathrm{Cl}$ residence toolkit it is important to underline that some community resilience tools, like the ones proposed by Sharifi and Yamagata [7] and Cutter et al. [12], includes the institutional dimension, which leads to a resilience appraisal of soft $\mathrm{Cls}$ resilience using both physical and management and organizational dimension of Liquefact toolkit.

\section{Conclusion}

This work presents the enhanced Liquefact $\mathrm{Cl}$ resilience assessment toolkit, which is suitable to the resilience appraisal of both hard and soft infrastructures. It encompasses indicators related to different sub-dimensions of Cls: finance, coordination capacity, business planning, physical asset, asset infrastructure, service design and service delivery. Its classification of the resilience indicators according to four resilience aspects points out the importance of all sub-dimensions in the system preparedness to EILDs and the involvement of most of system elements of physical and operational dimensions to absorb the effect of EILDs and recover after them. The adaptation ability of the system is seen as strongly related to organization and management of the system. Culture and capacity to learn from others are indicators, i.e. resilience elements, related to the social dimension of a $\mathrm{Cl}$ system; moreover, they inform other elements of the toolkit, such as regulations, planned redundancy, building code, DM and resilience budget planning, etc., in a new enhanced preparation and prevention to new disruptive events. Therefore, those indicators are the measure of the dynamics of the $\mathrm{Cl}$ system.

In conclusion, $\mathrm{Cl}$ resilience assessment toolkit defined so far within the Liquefact project can be improved to better define the interdependencies of $\mathrm{Cls}$; however, this would cause a reduction of its simplicity due to the hierarchic organizations of its elements/indicators, which is an additional strength of the toolkit. The future development of the toolkit will be the preparation of scorecard for its use.

\section{Acknowledge}

This project has received funding from the European Union's Horizon 2020 research and innovation programme under grant agreement No 700748.

\section{References}

[1] Shinozuka M., Chang S.E., Cheng T.-C., Feng M., O'Rourke T.D., Saadeghvaziri M.A., Dong X., Jin X., Wang Y., and Shi P. Resilience of Integrated Power and Water Systems. Buffalo, NY. MCEER Research Progress and Accomplishment; 2004 (MCEER-04-SP01)

[2] Tierney, K. and Bruneau, M. Conceptualizing and Measuring Resilience: A Key to Disaster Loss Reduction.TR News May-June 2007: 1417.

[3] Bruneau M., Chang S.E., Eguchi R.T., Lee G.C., O'Rourke T.D., Reinhorn A.M., Shinozuka M., Tierney K., Wallace W.A. and von Winterfeldt D. A Framework to Quantitatively Assess and Enhance the Seismic Resilience of Communities. Earthquake Spectra 2003; 19(4): 733-752.

[4] Proag V. Assessing and measuring resilience. $4^{\text {th }}$ International Conference on Building Resilience 2014, 8-10 September 2014, Salford Quays, UK. 
[5] Moench M. Adapting to climate change and the risks associated with other natural hazards: methods for moving from concepts to action. The earthscan reader on adaptation to climate change, Earthscan, London, 2009.

[6] Handmer J. and Dovers S. A typology of resilience: rethinking institutions for sustainable development. The earthscan reader on adaptation to climate change, Earthscan, London, 2009.

[7] Sharifi A., Yamagata Y. On the suitability of assessment tools for guiding communities towards disaster resilience. International journal of disaster risk reduction. 2016; 18 : 115-124.

[8] Larkin S., Fox-Lent C., Eisenberg D.A., Trump B.D., Wallace S., Chadderton C., Linkov I. Benchmarking agency and organizational practices in resilience decision making. Environmental systems and decisions. 2015; 36(3): 185-195.

[9] Scholz R.W., Blumer Y.B., Brand F.S. Risk, vulnerability, robustness, and resilience from a decision-theoretic perspective. Journal of risk research. 2011; 15(3): 313330.

[10] Bhamra R., Dani S., Burnard K. Resilience the concept, a literature review and future directions. International journal of production research. 2011; 49(18): 53755393.

[11] Ponomarov S.Y., Holcomb M.C. Understanding the concept of supply chain resilience. Intenational journal of logistics management. 2009; 20(1): 124-143.

[12] Cuttter S.L., Barnes L., Berry M., Burton C., Evans E., Tate E., Webb J. A place-based model for understanding community resilience to natural disasters. Global Environmental Change. 2008; 18:598-606.

[13] Rodriguez-Nick T. Linking disaster resilience and sustainability. Civil engineering and environmental systems. 2015; 32(1-2):157169.
[14] Berkeley A.R., Wallace M. A framework for establishing critical infrastructure resilience goals. National Infrastructure Advisory Council, 2010.

[15] Prior T. Measuring Critical Infrastructire resilience: possible indicators. Risk and Resilience Research Group, Center for Security Studies, ETH Zürich, 2015.

[16] Resilens. Deliverable 2.2: Qualitative, semiquantitative and quantitative methods and measures for resilience assessment and enhancement, 2016.

[17] Bartolucci A. Jones K. Deliverable 5.1: Report on individual stakeholder and urban community performance metrics. Version 1. Liquefact, 2017. 